\title{
The extent to which adequacy of staffing predicts nursing teamwork in hospitals
}

\author{
Helga Bragadóttir PhD, RN, Professor, Chair Nursing Administration ${ }^{1,2}$ (D) | \\ Beatrice J. Kalisch PhD, RN, FAAN, Titus Professor ${ }^{3}$ | \\ Gudný Bergthóra Tryggvadóttir MSc, Statistical Consultant ${ }^{4}$
}

${ }^{1}$ Faculty of Nursing, School of Health Sciences, University of Iceland, Reykjavik, Iceland

${ }^{2}$ Landspitali University Hospital, Reykjavik, Iceland

${ }^{3}$ School of Nursing, University of Michigan, Ann Arbor, MI, USA

${ }^{4}$ The Social Science Research Institute, University of Iceland, Reykjavik, Iceland

\section{Correspondence}

Helga Bragadóttir, Faculty of Nursing,

School of Health Sciences, University

of Iceland, Eirberg, Eiriksgata 34, 101

Reykjavik, Iceland.

Email: helgabra@hi.is

\section{Funding information}

This study was funded by research grants from the University of Iceland, LandspitaliUniversity Hospital and The Icelandic Nurses Association.

\begin{abstract}
Aims and objectives: The purpose of this study was to examine the extent to which staffing adequacy predicts nursing teamwork, controlling for demographic and background variables.

Background: Findings from former studies indicate that hospital, unit and staff characteristics may be related to nursing teamwork, such as type of hospital and unit, role, gender, age, work experience, type of shift worked, shift length, number of working hours per week, overtime and staffing adequacy. Teamwork as well as staffing is identified as significant contributors to patient and staff safety in hospitals. However, the contribution of staffing to the quality of nursing teamwork is scarcely studied.
\end{abstract}

Design: This was a quantitative descriptive cross-sectional study using the paperand-pencil questionnaire Nursing Teamwork Survey-Icelandic.

Methods: The study was conducted in 27 inpatient units in eight hospitals in Iceland with a sample of 925 nursing staff members. Participants were 567 registered nurses, practical nurses, unit secretaries and nurse unit managers. The Strengthening the Reporting of Observational Studies in Epidemiology checklist was used for this paper.

Results: When controlling for unit type, role, experience on current unit and intent to leave, perceived adequacy of staffing alone explains up to $10 \%$ of overall teamwork. Unit type, role, years of experience on current unit and perceived staffing adequacy correlated significantly with overall teamwork.

Conclusions: The findings of this study indicate that unit and staff characteristics, including perceived adequacy of staffing, are associated with and explain the variability in nursing teamwork on inpatient hospital units. The findings of this study provide important information for clinical nurses, nurse managers, policymakers and instructors in health care.

Relevance to clinical practice: The findings underline the importance of adequate staffing for nursing teamwork in inpatient hospital units.

\section{KEYWORDS}

nurses, nursing, staff, staffing, teamwork, hospitals 


\section{1 | INTRODUCTION}

For almost two decades, effective teamwork in health care has been recognised as an essential ingredient of the patient safety movement. Influential institutions such as the Institute of Medicine (IOM) and the World Health Organization (WHO) emphasise the importance of teamwork and team-based care (Kohn, Corrigan, \& Doran, 2000; Mitchell et al., 2012; WHO, 2009, 2011). Being competent in task work is not the same as being competent in teamwork, and for active teams, team members must be qualified in both skills (Morgan, Glickman, Woodard, Blaiwes, \& Salas, 1986). Teamwork needed in health care is both interdisciplinary (across disciplines) and within disciplines including nursing on each patient care unit, both are critical for quality outcomes (Van Bogaert et al., 2014; Bragadóttir, Kalisch, \& Tryggvadóttir, 2017; Chapman, Rahman, Courtney, \& Chalmers, 2016; Kalisch, 2015; Kalisch, Xie, \& Ronis, 2013). Indications are that good teamwork leads to better nursing care (Kalisch \& Lee, 2010), and less teamwork has been shown to be associated with poorer nursing staff outcomes such as intent to leave, less job satisfaction, burnout and work-family conflicts (Estryn-Behar et al., 2007; Kalisch, Lee, \& Rochman, 2010). Hospital and unit characteristics, such as type, size, staff skill mix and hours per patient day, are also shown to be associated with the level of nursing teamwork (Kalisch \& Lee, 2012, 2013; Siqueira, Caliri, Kalisch, \& Dantas, 2013). Study results also indicate a relationship between the level of teamwork with staff characteristics such as gender, age, working hours, absenteeism, role and perception of adequate staffing (Kalisch \& Lee, 2009, 2012, 2013). Staffing has gained specific attention as repeatedly studies show that level of nurse staffing and staff skill mix are predictive of preventable patient deaths and other adverse outcomes. Better patient outcomes occur with a higher skill mix of nurses and more nursing hours per patient day (Aiken, Cimiotti, et al., 2011; Aiken et al., 2014, 2017; Aiken, Sloane, et al., 2011; Cho et al., 2015; Kane, Shamliyan, Mueller, Duval, \& Wilt, 2007). Staffing and teamwork are, therefore, identified as two key elements in quality care. This study is being undertaken to identify the contribution of adequacy of staffing to nursing teamwork in hospital inpatient units, as identified by staff members, controlling for unit and staff characteristics.

\section{BACKGROUND}

A key team researcher, Dr. Eduardo Salas, developed a model which identifies five main components of teamwork (team leadership, mutual performance monitoring, backup behaviour, adaptability and team orientation) and three coordinating mechanisms (shared mental models, closed-loop communication and mutual trust) (Salas, Sims, \& Burke, 2005). A study by Kalisch, Weaver, and Salas (2009) demonstrated that the Salas model explains nursing teamwork in inpatient hospital units. The Salas model was also used as the basis of a survey tool to measure nursing teamwork-the Nursing Teamwork Survey (Kalisch, Lee, \& Salas, 2010). The psychometric testing of this tool yielded five subscales of nursing teamwork: trust, team orientation,

\section{What does this paper contribute to the wider global clinical community?}

- This paper identifies the contribution of staffing adequacy to the quality of nursing teamwork in inpatient hospital units.

- It further reveals the importance of identifying unit and staff characteristics which contribute to the quality of nursing teamwork, providing directions on what to target besides staffing, when working on quality improvements in hospitals.

backup, shared mental model and team leadership (Kalisch, Lee, \& Salas, 2010).

\section{1 | Hospital and unit characteristics and nursing teamwork}

Previous studies on nursing teamwork in hospitals indicate that teamwork may differ depending on type of hospital and unit. These studies are few in number, are all conducted in the USA and show somewhat mixed findings. In a study from 52 inpatient units in four hospitals with over 2,500 nursing staff participants, findings indicated a significant difference in teamwork based on size of hospital, showing a positive correlation between teamwork and number of hospital beds (Kalisch \& Lee, 2011). Another study, including almost 4,000 nursing staff from 95 patient care units in six hospitals, revealed a significantly different reverse relationship between the overall teamwork score and four out of five subscales of team care and size of hospital. The overall score for teamwork and the subscales of trust, team orientation, backup and shared mental model (SMM), were specifically higher in small hospitals compared to medium-sized and large hospitals (Kalisch $\&$ Lee, 2013). The findings of this study also showed a significant difference in teamwork between unit types for the overall score for teamwork as well as for each of the five subscales of teamwork: trust, team orientation, backup, SMM and team leadership. A post hoc test revealed the highest teamwork in psychiatric and perioperative units, followed by ICU and paediatric and maternity units, with medical-surgical, intermediate and rehabilitation units as lowest (Kalisch \& Lee, 2013). Yet other studies have shown diverse findings on the relationship of teamwork and unit type. In a study where over 2,000 nursing staff from 50 medical, surgical, intensive care and rehabilitation units in four hospitals participated, the level of teamwork was significantly higher in ICUs than other type of units (Kalisch \& Lee, 2010), and in a study with 1,414 nursing staff participants from 74 units within 11 hospitals including multiple types of services, overall teamwork scored best in rehabilitation with long term care scoring significantly lower (Kaiser \& Westers, 2018). 


\section{2 | Staff characteristics and nursing teamwork}

In studies conducted in the USA, indications are that a number of staff characteristics may be related to nursing teamwork, such as role, gender, age, work experience, type of shift worked, shift length, number of working hours per week and overtime. In a study of 11 hospitals with over 4,500 participants including nursing staff and nursing leaders from 124 medical-surgical, intermediate, intensive care and rehabilitation units, nurse leaders identified better teamwork than the nursing staff, with a statistically significant difference in trust, team orientation, SMM and team leadership (Kalisch \& Lee, 2012). Another study with almost 3,800 nursing staff member participants, indicated nurse leaders and unlicensed assistants evaluated nursing teamwork as higher than did registered nurses (Kalisch \& Lee, 2013). Female nursing staff reported significantly better overall teamwork than male staff members and older participants reported significantly higher scores on SMM, than younger participants (Kalisch \& Lee, 2009). Also, less experienced nursing staff rated nursing teamwork on their unit better than staff with more experience. Nursing staff with less than 6 months' work experience reported better overall teamwork as well as higher scores on the subscales of trust, team orientation and SMM. In addition, the less experienced group also reported significantly higher scores on team leadership than older participants (Kalisch \& Lee, 2009). The findings of another study from multiple specialty areas within 11 hospitals indicated that staff with up to 2 years' experience rated the teamwork on their unit significantly better than staff with more than 5 years' experience (Kaiser \& Westers, 2018). Nursing staff working night shifts reported teamwork significantly higher than those working day- and evening shifts (Kaiser \& Westers, 2018), and staff working nights had the highest scores on backup and team leadership (Kalisch \& Lee, 2009). Staff working 8- or 10-hr shifts reported the highest level of teamwork with those working a combination of 8- and 12-hr shifts reporting the lowest scores for teamwork (Kalisch \& Lee, 2009). Nursing staff working $30 \mathrm{hr}$ or less per week, and those working no overtime in the last 3 months, reported significantly better overall teamwork as well as better scores on the subscales of trust, team orientation, backup, SMM and team leadership, than did those working more than $30 \mathrm{hr}$ a week (Kalisch \& Lee, 2009), and nursing staff who were absent 2-6 shifts in the last 3 months reported less trust, team orientation and backup than did those who were not absent (Kalisch \& Lee, 2013). However, the study from Kaiser and Westers (2018), carried out in 74 units within 11 hospitals in the USA, with 1,414 nursing staff participants, showed a statistically non-significant relationship between gender and education with teamwork.

In summary indications are that leaders, less experienced staff, those working less than $30 \mathrm{hr}$ a week and those working no overtime, rate nursing teamwork higher.

\section{3 | Staffing}

Studies from around the world reveal that nurse staffing, nurses' education, skill mix and workload, as well as work environment, are related to patient mortality and other adverse outcomes (Aiken, Cimiotti, et al., 2011; Aiken et al., 2014, 2017; Aiken, Sloane, et al., 2011; Cho et al., 2015; Kane et al., 2007). Indications are that missed nursing care, an error of omission where necessary nursing care is missed or delayed severely, is higher with less staffing, whether measured with hours per patient days (Kalisch, Tschannen, \& Lee, 2011, 2012), self-report of nursing staff (Aiken et al., 2017; Cho et al., 2015; Sochalski, 2004; Zhu et al., 2012), or patient evaluation (Aiken et al., 2017; Dabney \& Kalisch, 2015; Zhu et al., 2012). Although indications are that both nurse staffing and nursing teamwork, play a pivotal role in patient and staff outcomes (Bragadóttir et al., 2017; Griffiths et al., 2018; Jones, Hamilton, \& Murry, 2015; Kalisch, 2015; Kalisch \& Xie, 2014), when preparing this study only three studies, all from the USA, were identified looking specifically at the relationship of these variables (Kaiser \& Westers, 2018; Kalisch \& Lee, 2009, 2011), all indicating a significant relationship of staffing and nursing teamwork. Findings of all three studies indicate that with adequate staffing there is better teamwork. A study including 1,802 nursing staff from 27 adult medical-surgical and intensive care units, and 11 paediatric and maternity units from a large academic health science centre in the USA, showed that staff that perceived the staffing on their unit to be adequate $100 \%$ of the time reported the highest teamwork scores, whereas staff that perceived the staffing on their unit adequate $50 \%$ or $0 \%$ of the time reported the lowest teamwork scores. Findings from the same study also showed that nurses taking care of fewer patient reported significantly better overall teamwork as well as more trust, team orientation, backup, SMM and team leadership (Kalisch \& Lee, 2009). Another study including over 2,500 nursing staff from 52 patient care units in four hospitals revealed that better teamwork was significantly related to more hours per patient day and greater nursing skill mix (Kalisch \& Lee, 2011).

\section{4 | Conceptual framework}

The conceptual framework of this study is based on the Salas model (Salas et al., 2005) of teamwork and Donabedian's three dimensions of quality health care: structure, process and outcomes (Donabedian, 1988). A nursing team is defined as the nursing staff members, including the nurse manager, registered nurses, practical nurses, unit secretaries, and other nursing assistive personnel, working on a given inpatient hospital care unit (Kalisch, Lee, \& Salas, 2010). These team members provide day-to-day patient care to a defined group of patients located in a geographically demarcated area of the hospital. The Salas model of teamwork identifies five core components of teamwork: (a) team leadership, (b) collective orientation, (c) mutual performance monitoring, (d) backup behaviour and (e) adaptability. The framework presumes interrelationships between the components enhanced by three coordinating mechanisms: (a) shared mental models, (b) closed-loop communication and (c) mutual trust (Kalisch et al., 2009; Salas et al., 2005). The Salas framework was identified to have a good fit to acute care nursing teams in a qualitative study from the USA were participants from 5 patient care units 
in one hospital where interviewed (Kalisch et al., 2009). In this study, variables within the structure dimension (hospital, unit and staff characteristics) and teamwork are examined.

\subsection{Aim}

The purpose of this study was to examine the extent to which staffing adequacy predicts nursing teamwork, controlling for demographic and background variables. The following research questions were raised:

1. What are the correlates of hospital, unit and staff characteristics including perceived levels of staffing adequacy, and the overall mean score of nursing teamwork, and mean scores of each of the subscales of the nursing teamwork factors: (1) trust, (2) team orientation, (3) backup, (4) shared mental model and (5) team leadership?

2. To what extent do hospital, unit and staff characteristics predict the variability in the overall nursing teamwork?

3. To what extent does perceived level of staffing adequacy predict the variability in overall nursing teamwork, controlling for unit and staff characteristics?

\section{3 | METHODS}

\section{1 | Design}

The study was a quantitative descriptive cross-sectional study using the paper-and-pencil questionnaire Nursing Teamwork Survey-Icelandic (NTS-Icelandic). A section of the questionnaire also asks about background and demographic variables including perceptions of staffing adequacy. This study is a part of a larger research project on missed nursing care and teamwork in hospitals in Iceland (Bragadottir, Kalisch, Smaradottir, \& Jonsdottir, 2016). The Strengthening the Reporting of Observational Studies in Epidemiology (STROBE) checklist was used for this paper, (See Appendix S1).

\section{2 | Sample}

The sample consisted of all ( $N=925)$ nursing staff in all inpatient medical, surgical and intensive care units in Iceland, a total of 27 units. Included were all nursing staff spending most of their working time on the particular unit. The units were in eight different healthcare facilities, all a part of the nationalised health care services in Iceland. The health care facilities included were one university hospital and one teaching hospital, both tertiary health care facilities with ICUs. The other hospitals were small regional hospitals in rural areas, most of which had one small mixed medical-surgical inpatient unit. The response rate ranged from $35 \%-$ $90 \%(n=18-71)$ per unit. For this study, data from 567 participants
(61\%) were used. Included in this study were all registered nurses (RNs), practical nurses (PNs), nurse unit managers and unit secretaries. The primary direct patient care providers in hospitals in Iceland are RNs and PNs. The vast majority of RNs in Iceland hold a baccalaureate degree in nursing and PNs are licensed healthcare personnel with a 3-year vocational level education. In hospitals in Iceland, PNs are defined as nursing assistive personnel working under the supervision of RNs.

\section{3 | Measures}

\subsection{1 | Characteristics of hospitals, units and staff}

Hospitals were categorised into two types of hospitals: teaching hospitals (one university hospital and one teaching hospital) and other hospitals (six regional hospitals). Patient units were further categorised into: medical units (11), surgical units (8), mixed medical and surgical units (5) and intensive care units (ICUs) (3). The mixed medical and surgical units were all in the small regional hospitals and all the ICUs were in the teaching hospitals. The staff characteristic variables used in this study were: gender, age, role (job title), number of hours worked per week, work hours, experience in role, experience on current unit, overtime, sick days, and intent to leave.

\subsection{2 | The Nursing Teamwork Survey}

The NTS-Icelandic is a translation of the Nursing Teamwork Survey developed in the USA (Kalisch, Lee, \& Salas, 2010). The NTS, both the US and Icelandic versions, have undergone rigorous testing processes of its acceptability, reliability and validity (Bragadottir et al., 2016; Kalisch, Lee, \& Salas, 2010). An exploratory factor analysis of the NTS indicated a 33-item model fit with five subscales: (1) trust with seven items, (2) team orientation with nine items, (3) backup with six items, (4) shared mental model with seven items and (5) team leadership with four items. The items in the NTS are put forward as statements. Participants are asked to answer by marking on a 5-point Likert-type scale to what extent each statement applies to their team. The values on the scale are (1) rarely, (2) $25 \%$ of the time, (3) $50 \%$ of the time, (4) $75 \%$ of the time and (5) always. A higher score indicates better teamwork.

The questionnaire was translated from US English to Icelandic using a rigorous back-translation method and tested psychometrically with data from a pilot-test and with data from this national study (Bragadottir et al., 2016). The Icelandic version of the survey tested to be acceptable, reliable and valid. Acceptability in the national study was based on data from 584 participants; $80.8 \%$ answered all the items. The overall test-retest intraclass correlation coefficient in the pilot study was 0.693 (lower bound $=0.498$, upper bound $=0.821 ; p<0.001$ ) and the Cronbach's alpha reliability for the total scale as well as the subscales ranged from 0.737-0.911. A confirmatory factor analysis showed a good fit of the national study data with the five-factor model of the NTS 
(Bragadottir et al., 2016; Kalisch, Lee, \& Salas, 2010). The NTS has repeatedly been used successfully with nursing staff in USA for studying teamwork in nursing (Kalisch, Lee, \& Rochman, 2010; Kalisch \& Lee, 2010, 2011, 2013; Kalisch et al., 2013). The questionnaire is also suitable for health care facilities to evaluate the functions and activities of their nursing teams (Kalisch, Lee, \& Salas, 2010).

\subsection{3 | Staffing}

The staffing variable used in this study was a measure of perceived adequacy of staffing on participants' units. Participants were asked how often they felt the unit staffing was adequate measured on a 5 -point Likert-scale with the options of " $0 \%$ of the time," " $25 \%$ of the time," " $50 \%$ of the time," " $75 \%$ of the time" and " $100 \%$ of the time." For the analysis of this variable, it was converted to a binary variable where the rates of " $0 \%$ of the time," " $25 \%$ of the time" and " $50 \%$ of the time" were combined and the rates of "75\% of the time" and "100\% of the time" were summed.

\subsection{Data collection}

Nurse managers on each patient care unit were contacted to introduce the study and to nominate a liaison for data collection. Nurse managers sent an introductory letter describing the study to all their nursing staff in the week before the data collection. The liaisons collected precise data on the number of staff in their unit and were in charge of distributing a questionnaire with a cover letter and a return envelope to each staff member. In all units outside the university hospital, the liaison person also collected the return envelopes and mailed them to the investigators. The participants at the university hospital could drop their return envelope in the next in-house mailbox on their units. A reminder letter was sent via e-mail to each of the nurse unit managers and liaison persons, 1 and 2 weeks following sending out the data collection materials. Data collection took about a month. Those units who reached at least $50 \%$ participation rate received a box of chocolates and twenty-five out of 27 units reached this goal. A thank-you letter was sent to all units following the data collection, and all the liaison persons also received a thankyou letter with a small token of acknowledgement.

\section{5 | Ethical considerations}

Participation was voluntary and completing the survey equalled a written informed consent. Before data collection, the study was approved by the Institutional Review Board in each hospital, or equivalent body in the smaller hospitals. The study was announced to the Data Protection Authorities of Iceland (S5388/2011).

\section{6 | Data analysis}

IBM sPss version 24.0 (IBM Corp.) was used for data analysis. The unit of analysis was the individual staff member. Demographic and background variables were defined as categorical variables and recorded as dummy variables. As the variables hospital and unit covariated, only the variable unit was used for the model testing. The variable of nursing teamwork was defined as a continuous variable. For teamwork, an overall mean score was calculated as well as a mean score for each subscale.

Frequency distributions, independent $t$ test and unilateral ANOVAs with the Tukey post hoc test were used to answer research question one. Hierarchical linear regression was used to answer research questions two and three about the relationship of the unit and staff characteristics, perceived staffing adequacy and nursing teamwork. The regression consisted of two hierarchies, where hierarchy one (Model 1) included the variables unit, role, experience on unit and intent to leave, with the addition of staffing in hierarchy two (Model 2). Model 1 tested to what extent unit and staff characteristics predicted the variance in nursing teamwork, and Model 2 tested the extent to which perceived staffing adequacy predicted the variance in nursing teamwork when controlling for unit and staff characteristics.

Missing data were not substituted. Cases with missing values were dropped for each statistical computation.

\section{4 | RESULTS}

The characteristics of hospital, unit and staff participants can be seen in Table 1. The majority of participants came from the teaching hospitals (79\%), and the medical (34.9\%) and surgical units (31\%). Most were females (98.6\%), between the age of 35-54 (54.1\%), RNs (57.7\%) or PNs (35.4\%). The vast majority worked rotating shifts (81.7\%) and 30 or more hours per week (76.1\%). In the past 3 months the majority of participants had worked some overtime $(73.5 \%)$ and had been absent one or none day or shift (53.7\%). The majority of participants had at least 5 years of experience in their current role (72\%) and on their current unit (55.9\%). The minority (12.1\%) had an intention to leave their job within the next year. When asked about staffing adequacy on their unit, 71\% of participants reported adequate staffing on their unit $75 \%$ or $100 \%$ of the time.

\section{1 | Hospital, unit and staff characteristics including staffing adequacy and nursing teamwork}

When testing for the correlation of hospital, unit and staff characteristics including perceived levels of staffing adequacy with overall nursing teamwork and each of the subscales of teamwork, statistically significant relationships where identified for the following variables: hospital, unit, age, role, years of experience on current unit and perceived adequacy of staffing (see Table 1). Significantly more backup was reported by participants in the teaching hospitals $(M=3.95, S D=0.64)$ than in other hospitals $(M=3.74, S D=0.62)$. The correlation of hospital type to the overall teamwork and the other four subscales were non-significant. 
TAB LE 1 Hospital, unit, staff characteristics, including perceived staffing adequacy and mean scores (M) with standard deviations (SD; scale range $1-5)$ for overall teamwork and subscales $(N=567)$

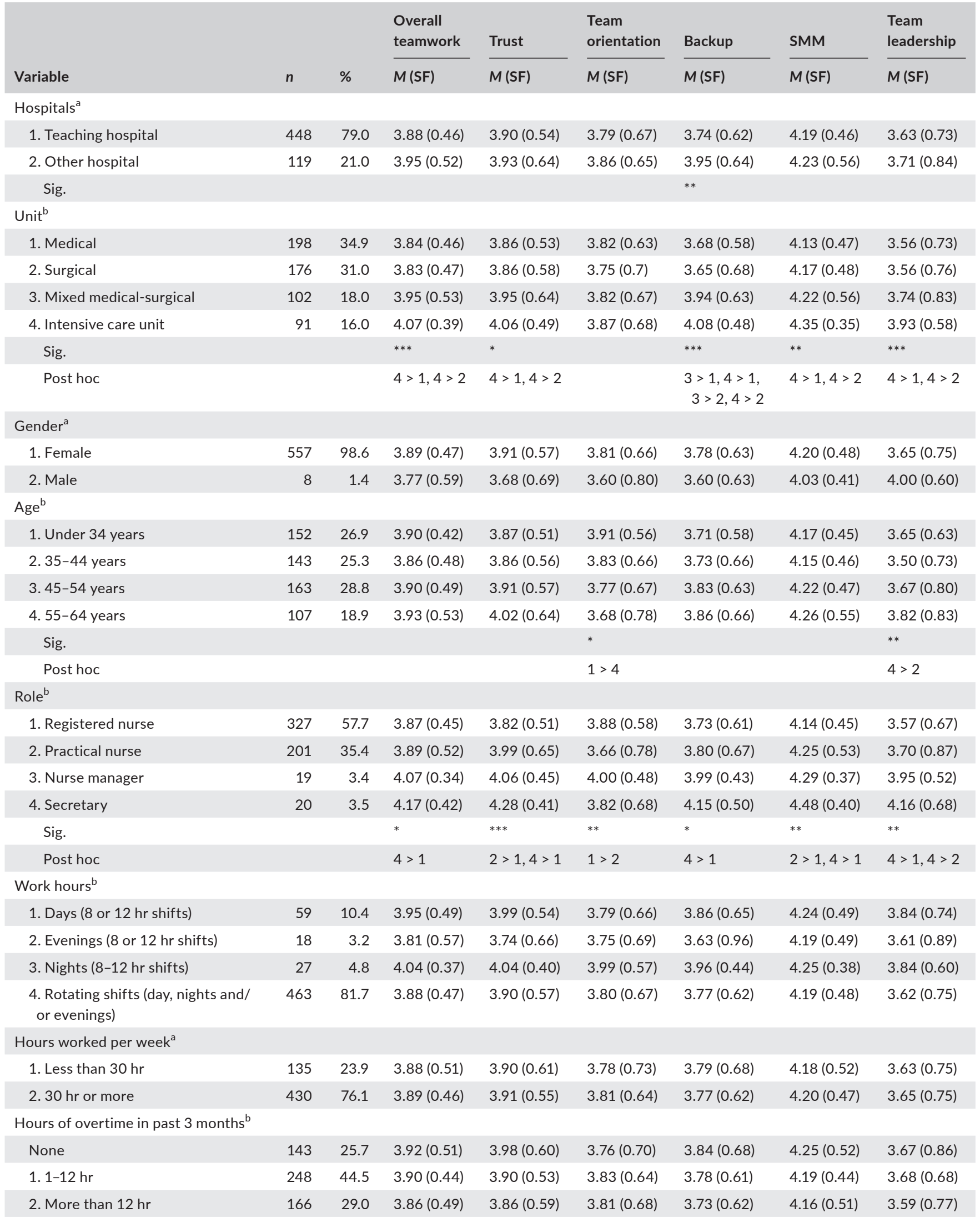


TABLE 1 (Continued)

\begin{tabular}{|c|c|c|c|c|c|c|c|c|}
\hline \multirow[b]{2}{*}{ Variable } & \multirow[b]{2}{*}{$n$} & \multirow[b]{2}{*}{$\%$} & \multirow{2}{*}{$\begin{array}{l}\begin{array}{l}\text { Overall } \\
\text { teamwork }\end{array} \\
M(S F)\end{array}$} & \multirow{2}{*}{$\frac{\text { Trust }}{M(\mathrm{SF})}$} & \multirow{2}{*}{$\begin{array}{l}\begin{array}{l}\text { Team } \\
\text { orientation }\end{array} \\
M(S F)\end{array}$} & \multirow{2}{*}{$\frac{\text { Backup }}{M(\mathrm{SF})}$} & \multirow{2}{*}{$\frac{S M M}{M(S F)}$} & \multirow{2}{*}{$\begin{array}{l}\begin{array}{l}\text { Team } \\
\text { leadership }\end{array} \\
M(S F)\end{array}$} \\
\hline & & & & & & & & \\
\hline 1. None-1 day or shift & 303 & 53.7 & $3.88(0.51)$ & $3.90(0.62)$ & $3.79(0.68)$ & $3.80(0.66)$ & $4.18(0.53)$ & $3.63(0.81)$ \\
\hline 2. 2 or more days or shifts & 261 & 46.3 & $3.91(0.44)$ & $3.91(0.5)$ & $3.83(0.66)$ & $3.76(0.60)$ & $4.22(0.42)$ & $3.68(0.68)$ \\
\hline 1. Up to 2 years & 75 & 13.4 & $3.92(0.51)$ & $3.91(0.62)$ & $3.90(0.68)$ & $3.71(0.59)$ & $4.21(0.54)$ & $3.70(0.69)$ \\
\hline 2. Greater than 2 years to 5 years & 82 & 14.6 & $3.90(0.42)$ & $3.89(0.50)$ & $3.81(0.54)$ & $3.78(0.61)$ & $4.21(0.42)$ & $3.68(0.62)$ \\
\hline 3. Greater than 5 years to 10 years & 99 & 17.7 & $3.84(0.44)$ & $3.83(0.51)$ & $3.83(0.71)$ & $3.68(0.66)$ & $4.13(0.43)$ & $3.52(0.75)$ \\
\hline 4. Greater than 10 years & 304 & 54.3 & $3.90(0.49)$ & $3.93(0.59)$ & $3.77(0.68)$ & $3.83(0.64)$ & $4.21(0.50)$ & $3.67(0.80)$ \\
\hline 3. Greater than 5 years to 10 years & 115 & 20.5 & $3.89(0.43)$ & $3.86(0.53)$ & $3.88(0.60)$ & $3.77(0.63)$ & $4.19(0.41)$ & $3.57(0.70)$ \\
\hline 4. Greater than 10 years & 199 & 35.4 & $3.92(0.50)$ & $3.98(0.58)$ & $3.77(0.72)$ & $3.87(0.62)$ & $4.24(0.52)$ & $3.66(0.81)$ \\
\hline Sig. & & & $*$ & $* *$ & $* *$ & * & & \\
\hline Post hoc & & & $1>2$ & $1>2,4>2$ & $1>2$ & $4>2$ & & \\
\hline \multicolumn{9}{|l|}{ Intent to leave ${ }^{a}$} \\
\hline 1. No intent to leave & 493 & 87.9 & $3.91(0.46)$ & $3.92(0.55)$ & $3.82(0.66)$ & $3.80(0.62)$ & $4.22(0.46)$ & $3.67(0.74)$ \\
\hline 2. Intent to leave within a year & 68 & 12.1 & $3.78(0.57)$ & $3.83(0.67)$ & $3.69(0.70)$ & $3.69(0.74)$ & $4.07(0.58)$ & $3.53(0.85)$ \\
\hline \multicolumn{9}{|l|}{ Perceived adequacy of staffing ${ }^{a}$} \\
\hline 1. $>50 \%$ of the time & 396 & 71.0 & $3.95(0.42)$ & $3.96(0.52)$ & $3.85(0.64)$ & $3.85(0.57)$ & $4.25(0.43)$ & $3.74(0.69)$ \\
\hline
\end{tabular}

Note: Significant difference: ${ }^{*} p<0.05 ;{ }^{* *} p<0.01 ;{ }^{* * *} p<0.001$.

${ }^{a}$ Independent $t$ test.

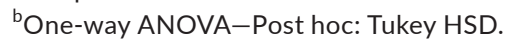

Unit type had a statistically significant relationship with overall teamwork and four of the subscales: trust, backup, SMM and team leadership. Overall teamwork was significantly higher in ICUs $(M=4.07, S D=0.39)$ than in medical units $(M=3.84, S D=0.46)$ and surgical units $(M=3.83, S D=0.47)$. The subscales of trust, backup, SMM and team leadership were also significantly higher in ICUs $(M=4.06, S D=0.49 ; M=4.08, S D=0.48 ; M=4.35, S D=0.35$; $M=3.93, S D=0.58$, respectively) than in medical units $(M=3.86$, $S D=0.53 ; M=3.68, S D=0.58 ; M=4.13, S D=0.47 ; M=3.56$, $S D=0.73$, respectively) and surgical units $(M=3.86, S D=0.58$; $M=3.65, S D=0.68 ; M=4.17, S D=0.48 ; M=3.56, S D=0.76$, respectively). Backup was also significantly higher in mixed medicalsurgical units $(M=3.94, S D=0.63)$ than in medical units $(M=3.68$, $S D=0.58)$ and surgical units $(M=3.65, S D=0.68)$.

Participants under the age of 34 reported that team orientation $(M=3.91, S D=0.56)$ was significantly higher than participants aged $55-64$ years $(M=3.68, S D=0.78)$. However, participants aged 55-64 years reported leadership significantly higher $(M=3.82$, $S D=0.83)$ than did participants aged $35-44$ years $(M=3.50$, $S D=0.73)$.
A statistically significant relationship was identified between role and overall nursing teamwork as well as all five subscales of teamwork. Secretaries reported higher overall teamwork $(M=4.17$, $S D=0.42)$, trust $(M=4.28, S D=0.41)$, backup $(M=4.15, S D=0.50)$, $\operatorname{SMM}(M=4.48, S D=0.40)$ and team leadership $(M=4.16, S D=0.68)$ than did RNs $(M=3.87, S D=0.45 ; M=3.82, S D=0.51 ; M=3.73$, $S D=0.61 ; M=4.14, S D=0.45 ; M=3.57, S D=0.67$, respectively). Secretaries also reported significantly higher team leadership than $\operatorname{did} P N s(M=3.70, S D=0.87)$. PNs reported significantly higher trust $(M=3.99, S D=0.65)$ and $S M M(M=4.25, S D=0.53)$ than did RNs ( $M=3.82, S D=0.51 ; M=4.14, S D=0.45$, respectively), but $\mathrm{RNs}$ reported significantly higher team orientation $(M=3.88, S D=0.58)$ than did PNs ( $M=3.66, S D=0.78)$.

A statistically significant difference was identified between years of experience on current unit and overall nursing teamwork and the subscales of trust, team orientation and backup. Participants with up to 2 years of experience on current unit reported overall teamwork to be significantly higher $(M=3.96, S D=0.48)$, as well as trust $(M=3.97$, $S D=0.57)$ and team orientation $(M=3.94, S D=0.61)$ than those with 2 years to 5 years experience $(M=3.77, S D=0.45 ; M=3.77, S D=0.55$; 
$M=3.66, S D=0.66)$. Those with over 10 years experience on current unit reported trust $(M=3.98, S D=0.58)$ and backup $(M=3.87$, $S D=0.62)$ significantly higher than those with 2 years to 5 years experience $(M=3.77, S D=0.55 ; M=3.63, S D=0.67)$.

Perceived adequacy of staffing was statistically significantly related to overall nursing teamwork as well as all of the five subscales. Participants who perceived the staffing on their unit adequate more than $50 \%$ of the time ( $75 \%$ or $100 \%$ of the time) reported higher overall teamwork $(M=3.95, S D=0.42)$ as well as higher trust $(M=3.96$, $S D=0.52)$, higher team orientation $(M=3.85, S D=0.64)$, higher backup ( $M=3.85, S D=0.57)$, higher SMM: $(M=4.25, S D=0.43)$ and higher team leadership $(M=3.75, S D=0.69)$, than participants who perceived staffing adequacy $50 \%$ or less of the time.

\subsection{Unit and staff characteristics and overall nursing teamwork}

Hierarchical linear regression was used to test Model 1. It indicated that unit, role, experience on current unit and intent to leave, predicted to a significant level overall teamwork (see Model 1, Table 2). Unit type is associated with overall teamwork. Participants in other units than ICUs rated overall teamwork significantly lower. The expected teamwork value is 0.24 points and 0.25 points lower for participants in medical and surgical units, respectively, and 0.14 points lower for participants in mixed medical-surgical units, than for those in ICUs.

Both RNs and PNs are less likely than secretaries to rate teamwork as high. Expected teamwork value is 0.35 points lower for RNs and 0.30 points lower for $\mathrm{PNs}$ than for secretaries when controlling for unit, experience at work and intent to leave.

Work experience on current unit is associated with overall teamwork. Expected teamwork value is 0.13 points higher for participants who have up to 2 years work experience on current unit, than participants who have longer experience.

No intent to leave in the next year is predictive of higher teamwork. Expected value of teamwork is 0.15 points higher for participants who have no intent to leave within the year, then for participants who have intentions to leave in the next year, when controlling for other variables in the model.

\subsection{Staffing adequacy and overall nursing teamwork}

When adding the variable of perceived adequacy of staffing to the model in hierarchy two (Model 2, Table 2), findings show a significant

TAB LE 2 Hierarchical linear regression to determine predictors of overall teamwork

\begin{tabular}{|c|c|c|c|c|c|c|c|c|}
\hline \multirow[b]{2}{*}{ Variables } & \multicolumn{4}{|l|}{ Model 1} & \multicolumn{4}{|l|}{ Model 2} \\
\hline & $B$ & $S E$ & $\beta^{\mathrm{a}}$ & $t$ & $B$ & SE & $\beta^{\mathrm{a}}$ & $t$ \\
\hline \multicolumn{9}{|l|}{ Unit } \\
\hline \multicolumn{9}{|l|}{$\operatorname{ICU}(\mathrm{R})$} \\
\hline Medical & -0.24 & 0.06 & -0.25 & $-4.06^{* * *}$ & -0.22 & 0.06 & -0.22 & $-3.72^{* * *}$ \\
\hline Surgical & -0.25 & 0.06 & -0.25 & $-4.16^{* * *}$ & -0.23 & 0.06 & -0.23 & $-3.81^{* * *}$ \\
\hline Mixed & -0.14 & 0.07 & -0.11 & $-2.02^{*}$ & -0.13 & 0.07 & -0.11 & -1.93 \\
\hline \multicolumn{9}{|l|}{ Role } \\
\hline \multicolumn{9}{|l|}{ Secretary (R) } \\
\hline $\mathrm{RN}$ & -0.35 & 0.11 & -0.36 & $-3.28^{* *}$ & -0.32 & 0.11 & -0.33 & $-3.01^{* *}$ \\
\hline $\mathrm{PN}$ & -0.30 & 0.11 & -0.30 & $-2.74^{* *}$ & -0.27 & 0.11 & -0.28 & $-2.55^{*}$ \\
\hline Nurse manager & -0.10 & 0.15 & -0.04 & -0.64 & -0.07 & 0.15 & -0.03 & -0.48 \\
\hline \multicolumn{9}{|l|}{ Experience on unit } \\
\hline \multicolumn{9}{|l|}{ Greater than 2 years (R) } \\
\hline Up to 2 years & 0.13 & 0.05 & 0.11 & $2.63^{*}$ & 0.12 & 0.05 & 0.10 & $2.47^{*}$ \\
\hline \multicolumn{9}{|l|}{ Intent to leave } \\
\hline \multicolumn{9}{|l|}{ In the next year (R) } \\
\hline No plans within the year & 0.15 & 0.06 & 0.10 & $2.46^{*}$ & 0.13 & 0.06 & 0.09 & $2.14^{*}$ \\
\hline \multicolumn{9}{|l|}{ Staffing } \\
\hline \multicolumn{9}{|l|}{$>50 \%$ of the time $(R)$} \\
\hline$\leq 50 \%$ of the time & & & & & 0.17 & 0.04 & 0.16 & $3.87^{* * *}$ \\
\hline$R^{2}$ & 0.08 & & & & 0.10 & & & \\
\hline Adjusted $R^{2}$ & 0.06 & & & & 0.09 & & & \\
\hline$F$ & $5.5^{* * *}$ & & & & $6.68^{* * *}$ & & & \\
\hline
\end{tabular}

${ }^{a}$ Standard coefficient.

Significant difference: ${ }^{*} p<0.05{ }^{* *} p<0.01 ;{ }^{* * *} p<0.001$. 
association of perceived staffing adequacy to overall teamwork. Expected overall teamwork value is 0.17 points higher for participants who perceive adequate staffing on their unit $>50 \%$ of the time compared to participants who perceived adequate staffing on their unit $0 \%-50 \%$ of the time, when controlling for other variables in the model.

\section{5 | DISCUSSION}

The findings of this study show that unit and staff characteristics, including perceived adequacy of staffing are associated with and explain the variability in nursing teamwork on inpatient hospital units. More specifically, regression analysis revealed that unit type, role, experience on current unit, intent to leave and perceived staffing adequacy predicted to a significant level the expected value of overall teamwork. When controlling for unit type, role, experience on current unit and intent to leave, perceived adequacy of staffing alone explains up to $10 \%$ of overall teamwork.

Overall teamwork was significantly higher in ICUs, among secretaries, those with up to 2 years work experience on current unit and those who perceived staffing adequate on their unit $75 \%$ or $100 \%$ of the time. Role and perceived adequacy of staffing were also significantly correlated to all subscales of teamwork: trust, team orientation, backup, SMM and team leadership. Secretaries rated the subscales of trust, backup, SMM and team leadership higher than did RNs, and team leadership higher than PNs. PNs, however, rated trust higher than RNs, and RNs rated team orientation higher than PNs. These findings may be a manifest of the different views and perceptions based on education and role within the nursing team and health care services (Danielsson et al., 2014; Perry, Carpenter, Challis, \& Hope, 2003). Secretaries are not direct patient care provides, and RNs have a different role than PNs in regard to work activities and responsibilities. In comparison to studies from the USA, a comparable trend is identified as nursing staff including RNs rate nursing teamwork lower than nurse leaders and unlicensed assistive personnel (Kalisch \& Lee, 2012, 2013).

The type of hospital correlated only with the subscale of backup where participants from the teaching hospitals reported higher backup than those from the other hospitals. Unit type, however, correlated significantly to overall nursing teamwork and four of the five subscales: trust, backup, SMM and team leadership. In all cases subscales of teamwork were higher in ICUs than in medical and surgical units, and backup was higher in mixed medical-surgical units than in medical and surgical units. These findings indicate that in the teaching hospitals, who also are the main acute care hospitals in the country, the only ones with ICUs, and employing the majority of the workforce of RNs in the country, the staffing models and skill mix are different than in the other hospitals who are small regional hospitals serving somewhat different groups of patients.

Former studies from the USA looking at the relationship of hospital size and unit type have shown somewhat diverse findings (Kalisch \& Lee, 2010, 2011). However, findings from two former studies from the USA show that overall teamwork as well as all subscales of teamwork was higher in ICUs than in most other types of units such as medical and surgical units (Kalisch \& Lee, 2010, 2013). Medical and surgical units in larger teaching hospitals may have high acuity patients and heavy patient turnover, whereas in the ICUs the patient nurse ratio is usually as low as one. Therefore, the nature of the hospitals and units seems to contribute to overall nursing teamwork as well as its subscales.

The age of participants correlated to two subscales of nursing teamwork, team orientation and team leadership, without correlating to the overall teamwork. The youngest group of participants, those under the age of 34 years rated team orientation significantly higher than those in the oldest age group of 55-64 years of age, but those in the oldest age group rated team leadership significantly higher than participants in the age group of 35-44 years of age. These findings indicate that perception and views of team orientation and team leadership may be bound to generations and or experience at work (Dols, Landrum, \& Wieck, 2010; Estryn-Behar et al., 2007; Robson \& Robson, 2015). Comparable findings were not found in former studies, although one study found that older participants reported significantly higher scores on SMM than did the younger ones (Kalisch \& Lee, 2009). On the other hand, in our study years of experience on current unit correlated to overall nursing teamwork and three of the subscales: trust, team orientation and backup. Participants with 2-5 years of work experience on their unit reported significantly lower overall nursing teamwork, team orientation and trust than participants with less than 2 years experience. Participants with over 10 years experience reported lower trust, and backup than did the participants with over 10 years experience. Former studies from the USA have also found an association of work experience on current unit and level of teamwork. The findings from the USA indicate participants with less experience such as up to 6 months or up to 2 years, rated overall teamwork and some of the subscales higher than did participants with more work experience on their unit (Kaiser \& Westers, 2018; Kalisch \& Lee, 2009). The first few years in nurses' work life and career development are known to be critical in terms of whether they intend to stay within the profession or not (Brunetto et al., 2013; Laschinger, 2012) and the younger generation may perceive important workplace issues differently than the older generations (Lavoie-Tremblay, Leclerc, Marchionni, \& Drevniok, 2010).

In our study other background variables, that is gender, work hours, hours worked per week, hours overtime, absenteeism, years of experience in role and intent to leave, did not correlate significantly with overall teamwork nor on the subscales of teamwork. These findings are in ways different from former studies from the USA (Kaiser \& Westers, 2018; Kalisch \& Lee, 2009, 2013), however those studies show diverse findings. These findings may indicate a more complex association of variables than tested in these studies, requiring further investigation of the broader picture of the interplay of workplace and staff characteristics as well as systems variables. In terms of our conceptual framework based on Donabedian's three dimensions of quality health care (Donabedian, 1988), in our study we 
are primarily looking at the structure part and partially the process part but not the outcomes.

The linear regression analysis of Model 1 showed that unit type, role, years of experience on current unit and intent to leave, all predicted to a significant level the expected value of overall teamwork. In total, these variables explained $8 \%$ of the expected variance in the overall teamwork. When controlling for these variables, Model 2 revealed that perceived adequacy of staffing alone explained up to $10 \%$ of expected variance in the overall teamwork. These findings indicate that staffing adequacy contributes significantly to nursing teamwork and are comparable to findings from the USA where staff who perceived staffing adequacy higher have significantly higher overall teamwork scores (Kalisch \& Lee, 2013) and with greater skill mix and more hours per patient day, overall nursing teamwork was higher (Kalisch \& Lee, 2011). The study from Kalisch and Lee (2013) with 3,769 nursing staff participants from six hospitals, revealed that role, full-time equivalency, type of shift worked, years of experience on unit, absenteeism, unit type and perceived staffing adequacy explained up to $18 \%$ of the variance in overall teamwork.

\section{1 | Strengths and limitations}

This study has both methodological strengths and limitations. Its main strengths are that the whole population of the nursing staff working in inpatient medical, surgical and intensive care units in Iceland made up the study sample. Another strength is the high response rate of $61 \%$. Yet, another methodological strength of this study is the use of reliable and valid tool which demonstrated good psychometric properties (Bragadottir et al., 2016). Although a small population, as used in this study, may be considered a methodological limitation, the homogeneity of communities such as the Icelandic one lends a strength to the study. Therefore, this study is a valuable contribution to the knowledge base of nursing as it serves as a significant step to understanding the larger context of the matter internationally. The main limitations are that the response rate for each unit varied, and the first time use of the questionnaire in Icelandic.

\section{6 | CONCLUSIONS}

In this study, the focus was on the contribution of unit type, role, experience on unit, intent to leave and perceived staffing adequacy to nursing teamwork. The study findings presented in this paper reveal that hospital, unit and staff characteristics, including staffing adequacy, are associated with and contribute significantly to nursing teamwork in hospital units.

Teamwork needs to be taught and trained, and special attention should be given to medical and surgical units, units where staffing is not considered adequate, RNs and PNs and their roles and responsibilities, staff with more than 2 years experience and staff who intend to leave. The nature of acute care medical and surgical inpatient units, with high acuity and rapid patient turnover, as well as the turning point of about 2 years experience in nurses career development, are variables of importance in association with staffing adequacy when it comes to the quality of overall nursing teamwork in hospitals as well as its subscales of trust, team orientation, backup, SMM and team leadership. The findings of this study provide important information for clinical nurses, nurse managers, policymakers and instructors in health care. However, the findings only shed light on parts of the complex interplay of multiple variables contributing to quality health care, manifesting the need for further studies on the matter of teamwork and related factors.

\section{7 | RELEVANCE TO CLINICAL PRACTICE}

The findings of this study shed light on the importance of adequate staffing levels to the achievement of nursing teamwork. This finding substantiates previous findings.

The importance of adequate staffing for teamwork is due to the fact that it takes time to participate as an effective team member. For example, if staffing is inadequate, it is not likely that team members will monitor and back one another up. They will not have time to give feedback to one another or to assist with caregiving such as ambulating patients requiring two individuals. Without enough staffing, there will be no time for backup or communication. Teamwork requires time. Research shows us that better teamwork results in safer care and this study shows that to have good nursing teamwork you have to have an adequate number of staff.

\section{CONFLICT OF INTEREST}

The authors declare no conflict of interest.

\section{ORCID}

Helga Bragadóttir (iD https://orcid.org/0000-0002-5616-8289

\section{REFERENCES}

Aiken, L. H., Cimiotti, J. P., Sloane, D. M., Smith, H. L., Flynn, L., \& Neff, D. F. (2011). Effects of nurse staffing and nurse education on patient deaths in hospitals with different nurse work environments. Medical Care, 49(12), 1047-1053. https://doi.org/10.1097/MLR.0b013e3182 $330 \mathrm{~b} 6 \mathrm{e}$

Aiken, L. H., Sloane, D. M., Bruyneel, L., Van den Heede, K., Griffiths, P., Busse, R., ... Sermeus, W. (2014). Nurse staffing and education and hospital mortality in nine European countries: A retrospective observational study. Lancet, 383(9931), 1824-1830. https://doi. org/10.1016/s0140-6736(13)62631-8

Aiken, L. H., Sloane, D. M., Clarke, S., Poghosyan, L., Cho, E., You, L., ... Aungsuroch, Y. (2011). Importance of work environments on hospital outcomes in nine countries. International Journal for Quality in Health Care, 23(4), 357-364. https://doi.org/10.1093/intqhc/mzr022

Aiken, L. H., Sloane, D., Griffiths, P., Rafferty, A. M., Bruyneel, L., McHugh, M., ... Sermeus, W. (2017). Nursing skill mix in European hospitals: Cross-sectional study of the association with mortality, patient ratings, and quality of care. BMJ Quality and Safety, 26(7), 559-568. https://doi.org/10.1136/bmjqs-2016-005567 
Bragadottir, H., Kalisch, B. J., Smaradottir, S. B., \& Jonsdottir, H. H. (2016). The psychometric testing of the Nursing Teamwork Survey in Iceland. International Journal of Nursing Practice, 22(3), 267-274. https://doi.org/10.1111/ijn.12422

Bragadóttir, H., Kalisch, B. J., \& Tryggvadóttir, G. B. (2017). Correlates and predictors of missed nursing care in hospitals. Journal of Clinical Nursing, 26(11-12), 1524-1534. https://doi.org/10.1111/jocn.13449

Brunetto, Y., Shriberg, A., Farr-Wharton, R., Shacklock, K., Newman, S., \& Dienger, J. (2013). The importance of supervisor-nurse relationships, teamwork, wellbeing, affective commitment and retention of North American nurses. Journal of Nursing Management, 21(6), 827-837. https://doi.org/10.1111/jonm.12111

Chapman, R., Rahman, A., Courtney, M., \& Chalmers, C. (2016). Impact of teamwork on missed care in four Australian hospitals. Journal of Clinical Nursing, 26, 170-181. https://doi.org/10.1111/jocn.13433

Cho, E., Sloane, D. M., Kim, E.-Y., Kim, S., Choi, M., Yoo, I. Y., ... Aiken, L. H. (2015). Effects of nurse staffing, work environments, and education on patient mortality: An observational study. International Journal of Nursing Studies, 52(2), 535-542. https://doi.org/10.1016/j. ijnurstu.2014.08.006

Dabney, B. W., \& Kalisch, B. J. (2015). Nurse staffing levels and patientreported missed nursing care. Journal of Nursing Care Quality, 30(4), 306-312. https://doi.org/10.1097/ncq.0000000000000123

Danielsson, M., Nilsen, P., Ohrn, A., Rutberg, H., Fock, J., \& Carlfjord, S. (2014). Patient safety subcultures among registered nurses and nurse assistants in Swedish hospital care: A qualitative study. BMC Nursing, 13(1), 39. https://doi.org/10.1186/s12912-014-0039-5

Dols, J., Landrum, P., \& Wieck, K. L. (2010). Leading and managing an intergenerational workforce. Creative Nursing, 16(2), 68-74. https:// doi.org/10.1891/1078-4535.16.2.68

Donabedian, A. (1988). The quality of care. How can it be assessed? JAMA, 260(12), 1743-1748. https://doi.org/10.1001/jama.1988.03410 120089033

Estryn-Béhar, M., Van der Heijden, B. I. J. M., Ogińska, H., Camerino, D., Le Nézet, O., Conway, P. M., ... Hasselhorn, H.-M. (2007). The impact of social work environment, teamwork characteristics, burnout, and personal factors upon intent to leave among European nurses. Medical Care, 45(10), 939-950. https://doi.org/10.1097/MLR.0b013 e31806728d8

Griffiths, P., Recio-Saucedo, A., Dall'Ora, C., Briggs, J., Maruotti, A., Meredith, P., ... Ball, J. (2018). The association between nurse staffing and omissions in nursing care: A systematic review. Journal of Advanced Nursing, 74(7), 1474-1487. https://doi.org/10.1111/ jan.13564

Jones, T. L., Hamilton, P., \& Murry, N. (2015). Unfinished nursing care, missed care, and implicitly rationed care: State of the science review. International Journal of Nursing Studies, 52(6), 1121-1137. https://doi. org/10.1016/j.ijnurstu.2015.02.012

Kaiser, J. A., \& Westers, J. B. (2018). Nursing teamwork in a health system: A multisite study. Journal of Nursing Management, 26(5), 555562. https://doi.org/10.1111/jonm.12582

Kalisch, B. J. (2015). Errors of omission: How missed nursing care imperils patients. Silver Spring, MD: American Nurses Association.

Kalisch, B. J., \& Lee, H. (2009). Nursing teamwork, staff characteristics, work schedules, and staffing. Health Care Management Review, 34(4), 323-333. https://doi.org/10.1097/HMR.0b013e3181aaa920

Kalisch, B. J., Lee, H., \& Rochman, M. (2010). Nursing staff teamwork and job satisfaction. Journal of Nursing Management, 18(8), 938-947. https://doi.org/10.1111/j.1365-2834.2010.01153.x

Kalisch, B. J., Lee, H., \& Salas, E. (2010). The development and testing of the nursing teamwork survey. Nursing Research, 59(1), 42-50. https:// doi.org/10.1097/NNR.0b013e3181c3bd42

Kalisch, B. J., \& Lee, K. H. (2010). The impact of teamwork on missed nursing care. Nursing Outlook, 58(5), 233-241. https://doi.org/10.1016/j. outlook.2010.06.004
Kalisch, B. J., \& Lee, K. H. (2011). Nurse staffing levels and teamwork: A cross-sectional study of patient care units in acute care hospitals. Journal of Nursing Scholarship, 43(1), 82-88. https://doi. org/10.1111/j.1547-5069.2010.01375.x

Kalisch, B. J., \& Lee, K. H. (2012). Congruence of perceptions among nursing leaders and staff regarding missed nursing care and teamwork. The Journal of Nursing Administration, 42(10), 473-477. https:// doi.org/10.1097/NNA.0b013e31826a1fa4

Kalisch, B. J., \& Lee, K. H. (2013). Variations of nursing teamwork by hospital, patient unit, and staff characteristics. Applied Nursing Research, 26(1), 2-9. https://doi.org/10.1016/j.apnr.2012.01.002

Kalisch, B. J., Tschannen, D., \& Lee, K. H. (2011). Do staffing levels predict missed nursing care? International Journal for Quality in Health Care, 23(3), 302-308. https://doi.org/10.1093/intqhc/mzr009

Kalisch, B. J., Tschannen, D., \& Lee, K. H. (2012). Missed nursing care, staffing, and patient falls. Journal of Nursing Care Quality, 27(1), 6-12. https://doi.org/10.1097/NCQ.0b013e318225aa23

Kalisch, B. J., Weaver, S. J., \& Salas, E. (2009). What does nursing teamwork look like? A qualitative study. Journal of Nursing Care Quality, 24(4), 298-307. https://doi.org/10.1097/NCQ.0b013e3181a001c0

Kalisch, B. J., \& Xie, B. (2014). Errors of omission: Missed nursing care. Western Journal of Nursing Research, 36(7), 875-890. https://doi. org/10.1177/0193945914531859

Kalisch, B. J., Xie, B., \& Ronis, D. L. (2013). Train-the-trainer intervention to increase nursing teamwork and decrease missed nursing care in acute care patient units. Nursing Research, 62(6), 405-413. https:// doi.org/10.1097/NNR.0b013e3182a7a15d

Kane, R. L., Shamliyan, T. A., Mueller, C., Duval, S., \& Wilt, T. J. (2007). The association of registered nurse staffing levels and patient outcomes: Systematic review and meta-analysis. Medical Care, 45(12), 1195-1204. https://doi.org/10.1097/MLR.0b013e3181468ca3

Kohn, L. T., Corrigan, J. M., \& Doran, D. M. (2000). To err is human: Building a safer health system. Washington, DC: National Academy Press.

Laschinger, H. K. (2012). Job and career satisfaction and turnover intentions of newly graduated nurses. Journal of Nursing Management, 20(4), 472-484. https://doi.org/10.1111/j.1365-2834.2011.01293.x

Lavoie-Tremblay, M., Leclerc, E., Marchionni, C., \& Drevniok, U. (2010). The needs and expectations of generation $\mathrm{Y}$ nurses in the workplace. Journal for Nurses in Staff Development (JNSD), 26(1), 2-8; quiz 9-10. https://doi.org/10.1097/NND.0b013e3181a68951

Mitchell, P., Wynia, M., Golden, R., McNellis, B., Okun, S., Webb, C. E., ... Von Kohorn, I. (2012). Core principles \& values of effective team-based health care. Discussion paper, Institute of Medicine, Washington, DC.

Morgan, B. B., Glickman, A. S., Woodard, E. A., Blaiwes, A. S., \& Salas, E. (1986). Measurement of team behaviors in a navy environment. Orlando, FL: Naval Training Systems Center.

Perry, M., Carpenter, I., Challis, D., \& Hope, K. (2003). Understanding the roles of registered general nurses and care assistants in UK nursing homes. Journal of Advanced Nursing, 42(5), 497-505. https://doi. org/10.1046/j.1365-2648.2003.02649.x

Robson, A., \& Robson, F. (2015). Do nurses wish to continue working for the UK National Health Service? A comparative study of three generations of nurses. Journal of Advanced Nursing, 71(1), 65-77. https:// doi.org/10.1111/jan.12468

Salas, E., Sims, D. E., \& Burke, C. S. (2005). Is there a "big five" in teamwork? Small Group Research, 36(5), 555-599. https://doi. org/10.1177/1046496405277134

Siqueira, L. D., Caliri, M. H., Kalisch, B., \& Dantas, R. A. (2013). Cultural adaptation and internal consistency analysis of the MISSCARE Survey for use in Brazil. Revista Latino-Americana De Enfermagem, 21(2), 610617. https://doi.org/10.1590/S0104-11692013000200019

Sochalski, J. (2004). Is more better? The relationship between nurse staffing and the quality of nursing care in hospitals. Medical Care, 42(2 Suppl), li67-li73. https://doi.org/10.1097/01.mlr.0000109127. 76128.aa 
Van Bogaert, P., Timmermans, O., Weeks, S. M., van Heusden, D., Wouters, K., \& Franck, E. (2014). Nursing unit teams matter: Impact of unit-level nurse practice environment, nurse work characteristics, and burnout on nurse reported job outcomes, and quality of care, and patient adverse events-a cross-sectional survey. International Journal of Nursing Studies, 51(8), 1123-1134. https://doi.org/10.1016/j.ijnur stu.2013.12.009

WHO (2009). Human factors in patient safety: Review of topics and tools. Geneva, Switzerland: World Health Organization.

WHO (2011). WHO patient safety curriculum guide: Multi-professional edition. Geneva, Switzerland: World Health Organization.

Zhu, X.-W., You, L.-M., Zheng, J., Liu, K. E., Fang, J.-B., Hou, S.-X., ... Zhang, L.-F. (2012). Nurse staffing levels make a difference on patient outcomes: A multisite study in Chinese hospitals. Journal of Nursing Scholarship, 44(3), 266-273. https://doi.org/10.1111/ j.1547-5069.2012.01454.x

\section{SUPPORTING INFORMATION}

Additional supporting information may be found online in the Supporting Information section at the end of the article.

How to cite this article: Bragadóttir $\mathrm{H}$, Kalisch $\mathrm{BJ}$, Bergthóra Tryggvadóttir $\mathrm{G}$. The extent to which adequacy of staffing predicts nursing teamwork in hospitals. J Clin Nurs.

2019;28:4298-4309. https://doi.org/10.1111/jocn.14975 